\title{
Risk Identification of Seismic Landslides by Joint Newmark and RockFall Analyst Models: A Case Study of Roads Affected by the Jiuzhaigou Earthquake
}

\author{
Xiliu Yue ${ }^{1,2} \cdot$ Shaohong $\mathrm{Wu}^{1,2} \cdot$ Yunhe Yin $^{1} \cdot$ Jiangbo Gao $^{1} \cdot$ Jingyun Zheng $^{1,2}$
}

Published online: 17 September 2018

(C) The Author(s) 2018

\begin{abstract}
Geological disasters are a great threat to people's lives and property. At present, it is difficult to evaluate quantitatively the cascading effects of regional geological disasters, and the development of new methods for such evaluation is much needed. In this study, the authors have developed a joint procedure that couples the Newmark model and the RockFall Analyst model based on a GIS platform in order to identify the impact of seismic landslides on roads. The new method effectively combines two processes-seismic landslide occurrence probability analysis and mass movement trajectory simulation. The permanent displacement derived from the Newmark model is used to identify potential source areas of landslides. Based on the RockFall Analyst model, the possible impact of mass movement on the roads can be simulated. To verify the reliability of the method, the landslides induced by the 2017 Jiuzhaigou Earthquake were taken as a case study. The results suggest that about $21.37 \%$ of the study area is at high risk of seismic landslides, and approximately $3.95 \mathrm{~km}$ of road sections are at extremely high risk of large landslides. The simulated area is consistent with the distribution of disasters revealed by post-earthquake remote sensing image interpretation and field investigation in existing studies. This indicates that the procedure, which joins the Newmark and RockFall models, has a high
\end{abstract}

Shaohong Wu

wush@igsnrr.ac.cn

1 Institute of Geographic Sciences and Natural Resources Research, Chinese Academy of Sciences, Key Laboratory of Land Surface Pattern and Simulation, Beijing 100101, China

2 University of Chinese Academy of Sciences, Beijing 100101, China reliability for risk identification and can be applied to seismic landslide risk assessment and prediction in similar areas.

Keywords China, Jiuzhaigou earthquake $\cdot$ Newmark model $\cdot$ Risk identification $\cdot$ RockFall analyst model $\cdot$ Seismic landslide

\section{Introduction}

Seismic landside is one of the common disasters in mountainous areas. It is widely reported hat a large number of landslides have been induced by catastrophic earthquakes (Cui et al. 2008; Owen et al. 2008; Chen et al. 2016). Serious economic losses and casualties were caused by these earthquakes and secondary disasters (Parsons et al. 2009; Sun et al. 2013; Zhang et al. 2014). Among them, the losses and casualties related to secondary disasters are believed to be much greater than those caused by the earthquakes themselves (Bai et al. 2012; Rodríguez-Peces et al. 2014). According to research on the variation tendency of geological hazards affected by earthquakes, such as the Kanto, Chi-chi, and Wenchuan earthquakes, the active period of landslides may last 5-10 years after the initial seismic event (Cui et al. 2008; Chen et al. 2018). Therefore, studies are specifically needed to assess the immediate cascading effects of disasters as well as their delayed effects (Shi et al. 2010; Kappes et al. 2012). It is still a major challenge to evaluate adequately and quantitatively the regional cascading effects of a seismic landslide, and the development of new or improved methods for evaluation of these impacts thus is of great significance.

Generally, different assessment models can be used in studies of seismic landslide risk. Among them, pseudo- 
static analysis, finite element modeling, and the Newmark model are often used to describe slope behavior under seismic stress. Pseudo-static analysis is useful in identifying yield accelerations and hence peak ground accelerations (PGAs) below which no slope displacement will occur (Seed et al. 1975). Because pseudo-static analysis provides only a single numerical threshold, many slopes experience transient earthquake accelerations well above their yield accelerations, but little or no permanent displacement occurs (Wilson and Keefer 1983; Jibson 1993). The clear mechanical concept of pseudo-static analysis encourages its wide use in engineering (Leshchinsky and Ka-Ching 1994; Ling and Cheng 1997; Biondi et al. 2002). Finite element modeling is a method that has facilitated very accurate evaluations of permanent slope deformations (Seed et al. 1975; Elgamal et al. 1987; Sun et al. 2013). These highly sophisticated methods require a broad spectrum of data of extremely high quality and density as well as intensive computing capacity, which is not always easily realized. Newmark's method models a landslide as a rigidplastic friction block with a known critical acceleration; when acceleration overcomes frictional resistance, sliding is initiated on an inclined plane (Newmark 1965; Wilson and Keefer 1983). Based on the calculation of cumulative permanent displacement, the analysis investigates seismic slope stability (Jibson 1993). Because the Newmark model yields much more useful information than pseudo-static analysis and is far more practical than finite element modeling, it has been used widely in both specific slope analyses (Jibson and Keefer 1993; Bray and Rathje 1998; Pradel et al. 2005) and regional landslide hazard assessments (Jibson et al. 2000; Del Gaudio 2003). Although seismic landslide assessment models can evaluate slope stability well, they cannot reflect trajectories of unstable rock masses and landslide depositional magnitudes, which are of great importance in determining the impact of a large landslide on specific infrastructure such as roads.

For the purpose of reflecting the trajectories of landslides, rockfall models are helpful tools. A rockfall is a rapid mass movement generated by the detachment of a rock volume from a slope that falls, rolls, and bounces along its trajectory. The modeling of physical rockfall processes considers the detachment of rock fragments, falling or flying, and their subsequent bouncing, fragmentation, rolling or sliding, and final deposition (Evans and Hungr 1993; Guzzetti et al. 2002; Lan et al. 2007). These dynamic processes are dominated by spatially and temporally distributed attributes such as detachment conditions, geometric features, and the mechanical properties of both rock blocks and slopes (Lan et al. 2007). Particularly important among the mechanical properties are static and dynamic friction, roughness, rolling resistance, restitution characteristics, and fragmentation ratios. Currently, modeling physical rockfall processes is a widely used tool for assessing rockfall hazards (Dorren 2003; Lan et al. 2007; Pizziolo 2015). Many studies have found that the corresponding models are highly useful for the risk identification of landslides (points or cracks) on roads, rivers, and buildings or other infrastructure (Guzzetti et al. 2004; Lan et al. 2007; Qi et al. 2015; Macciotta et al. 2016). Using the rockfall model to supplement the Newmark model could facilitate trajectory simulations of instable rock masses after seismic landslide occurrence probability assessments.

This article presents a joint procedure that couples the regional probability model of Newmark and the physical RockFall Analyst model. These tools can be used to analyze the seismic landslide occurrence probability as well as to simulate the trajectories of dangerous rock masses and to realize seismic landslide risk identification on specific infrastructure such as roads. The reliability of this method is then verified by interpretation of the post-earthquake remote sensing and field investigation of landslides induced by the Jiuzaigou Earthquake. The joint modeling and case study described in this article provide an example of and benchmark for earthquake-landslide chain risk identification on specific hazard-bearing objects such as roads and bridges.

\section{Method}

Risk assessment always tries to answer the question: how safe is the element at risk? The risk is usually defined by the product of hazard probability and the undesirable consequence of loss: $R=H \times V \times E$ in which $H$ (stands for hazard) indicates the probability of the occurrence of a hazard, $V$ represents vulnerability to specific hazard intensity, and $E$ is the exposure of the element at risk. This expression shows that risk level is closely related to the probability and the intensity of hazard. We therefore developed a joint procedure by coupling the Newmark model and the RockFall Analyst model to identify the risk exposure of the object (road) to seismic landslides. Each model accomplishes specific objectives: the Newmark model is used for seismic landslide probability analysis, and the Rockfall Analyst model is used for further unstable mass movement trajectory simulation.

\subsection{Basic Models}

The Newmark model and the Rockfall Analyst model are the two basic models used for our joint procedure. We first introduce the theory and algorithm of these two basic models. 


\subsubsection{The Newmark Model}

The Newmark model is used to estimate the expected seismic displacements of a landslide based on a given recorded acceleration (Newmark 1965). It simplifies slope instability as a rigid block sliding on an inclined surface. The critical acceleration is the seismic acceleration that causes the rigid block to be in a limited equilibrium state (Newmark 1965; Jibson 1993). Under an earthquake load, when the seismic acceleration exceeds the critical value of slope instability, the rigid block may slide along the failure surface, and permanent displacement will accumulate in the downward direction (Newmark1965; Jibson 1993, 2007). The critical acceleration can be calculated using the following formulas (Newmark 1965; Jibson 1993):

$a_{\mathrm{c}}=(\mathrm{Fs}-1) g \sin \alpha$

where $\alpha$ is the slope angle, $g$ is the acceleration due to gravity, and Fs is the static safety factor, which can be expressed as follows (Jibson et al. 2000):

Fs $=\frac{c^{\prime}}{\gamma t \sin \alpha}+\frac{\tan \varphi^{\prime}}{\tan \alpha}+\frac{m \gamma_{\mathrm{w}} \tan \varphi^{\prime}}{\gamma \tan \alpha}$

where $c^{\prime}$ is the effective cohesion, $\varphi^{\prime}$ is the effective friction angle, $\gamma$ is the material unit weight, $\gamma_{\mathrm{w}}$ is the unit weight of water, $t$ is the normal thickness of the sliding plane, and $m$ is the degree of saturation of the failure surface. In this study, we assumed that there is no effect of groundwater seepage, that is, the safety factor is calculated using the infinite slope model under completely dry conditions.

In the past three decades, much effort has been made to develop regression equations to describe the empirical relationships between seismic shaking parameters (including PGA, Arias intensity, and seismic intensity) and estimated landslide displacements (Jibson 2007; Saygili and Rathje 2008; Rathje and Saygili 2009; Rathje and Antonakos 2011; Chousianitis et al. 2014; Yuan et al. 2016), which allow quick estimates of the Newmark displacements of earthquake-induced landslides under different earthquake conditions. PGA and Arias intensity are the two key seismic parameters required for the Newmark model. Unlike PGA, which simply presents a single point during the acceleration time history, Arias intensity is a measure that includes the characteristics of amplitude, frequency content, and duration of ground motion (Arias 1970; Jibson 1993). Therefore, Arias intensity is considered superior or more appropriate than other seismic parameters in earthquake-induced landslide evaluations. Arias intensity has been demonstrated in various studies to be an effective predictor of earthquake damage potential in relation to seismic slope stability and correlates well with earthquake- induced landslide distribution (Jibson 1993; Harp and Wilson 1995; Hsieh and Lee 2011; Chousianitis et al. 2014).

In this study, however, the lack of seismic stations and strong-motion recordings limits the applicability of the Arias intensity to regional seismic landslide risk assessment, and we therefore adopted the regression model of $a_{\mathrm{c}} l$ $a_{\max }$ proposed by Jibson (2007). This expression is obtained through the regression analysis of data derived from a collection of 2270 strong-motion records obtained from 30 earthquakes worldwide $(5.3 \leq M \leq 7.6)$, and is used to simulate seismic-induced permanent slope displacement. This regression model can be expressed as follows:

$$
\begin{aligned}
\log D_{n}= & 0.215+\log \left[\left(1-\frac{a_{\mathrm{c}}}{a_{\max }}\right)^{2.341}\left(\frac{a_{\mathrm{c}}}{a_{\max }}\right)^{-1.438}\right] \\
& \pm 0.51
\end{aligned}
$$

where $D_{n}$ is the slope displacement, $a_{\mathrm{c}}$ is the critical acceleration, and $a_{\max }$ is the PGA. The above equation indicates that when $a_{\mathrm{c}} / a_{\max }$ is larger than $1, D_{n}$ will be a meaningless value.

Since the predicted Newmark displacements are related to different probabilities of landslide occurrence (Jibson et al. 2000), regional studies on probabilistic evaluations of earthquake-induced landslides therefore can be conducted (Del Gaudio 2003; Chousianitis et al. 2016; Zhang et al. 2017). These equations could help to identify thresholds of permanent displacement with different degrees of probability. In this study, the landslide probability from Jibson et al. (2000) was cited to calculate the threshold of permanent displacement for maximum landslide probability. The equation of landslide occurrence probability Pf is expressed as follows:

Pf $=0.335 \times\left[1-e^{\left(-0.048 \times D_{n}^{1.565}\right)}\right]$

\subsubsection{RockFall Analyst Model}

RockFall Analyst is a 3D solid motion model that is capable of effectively handling large amounts of geospatial information relevant to rockfall behaviors (Lan et al. 2007). It includes two major parts: (1) 3D rockfall trajectory simulations; and (2) raster modeling of the spatial distribution of rockfalls. As the RockFall Analyst model considers dynamic processes on a cell plane basis, it is wellsuited for the occurrence analysis of hazards that vary both spatially and temporally. The rockfall trajectory is the main part of the RockFall Analyst model, and the "lumped mass" or point approach is used in the RockFall Analyst model to simulate rockfall trajectories. As the physical 
processes of rockfalls are simulated through the RockFall Analyst model by considering the ground topography and a range of physical parameters (such as normal restitution coefficient, tangential restitution coefficient, and friction angle) during the generation of rockfall multiscenarios, the RockFall Analyst model provides a method of exploring the spatial data related to rockfalls (for instance, the rockfall frequency and energy) and examining their directional variations. In addition, a barrier analysis tool is provided in RockFall Analyst to aid barrier design. The physical attributes of boulders, such as their positions, displacements, velocities, accelerations, forces, and momenta, are represented in a 3D vector space. The input parameters include a seeder feature, a material composition feature, and a digital elevation model (DEM) raster.

The falling or flight path of a boulder is computed using a parabolic equation, which is defined as follows:

$\bar{x}=\left[\begin{array}{c}0 \\ 0 \\ -\frac{1}{2} g t^{2}\end{array}\right]+\left[\begin{array}{c}V_{x 0} \\ V_{y 0} \\ V_{Z 0}\end{array}\right] t+\left[\begin{array}{c}X_{0} \\ Y_{0} \\ Z_{0}\end{array}\right]$

where $g$ is the acceleration due to gravity $\left(9.8 \mathrm{~m} / \mathrm{s}^{2}\right), X_{0}, Y_{0}$, and $Z_{0}$ are the coordinates of the initial position, and $V_{x 0}$, $V_{y 0}$, and $V_{z 0}$ represent the initial velocity of the rock in the $x, y$, and $z$ directions, respectively. The velocity vector of the rockfall is defined as

$\bar{v}=\left[\begin{array}{c}V_{x 0} \\ V_{y 0} \\ V_{z 0}-g t\end{array}\right]=\left[\begin{array}{c}0 \\ 0 \\ -g t\end{array}\right]+\left[\begin{array}{c}V_{x 0} \\ V_{y 0} \\ V_{z 0}\end{array}\right]$

At the end of the flight path, which represents the intersection of the defined surface raster and the flight path of the rock, the rebound/bouncing velocity vector in a local coordinate system is defined as follows:

$V_{\text {Dip }}^{\prime}=V_{\text {Dip }} R_{\mathrm{T}}$

$V_{\text {Trend }}^{\prime}=V_{\text {Trend }} R_{\mathrm{T}}$

$V_{\mathrm{N}}^{\prime}=V_{\mathrm{N}} R_{\mathrm{N}}$

where $V_{\text {Dip }}, V_{\text {Trend }}$, and $V_{\mathrm{N}}$ represent the bouncing velocity vector without energy loss, $V_{\text {Dip }}$ is the velocity component of the rock in the dip direction of the slope cell, $V_{\text {Trend }}$ is the velocity component of the rock in the trend direction, $V_{N}$ is the velocity component of the rock in the normal direction of the slope cell, $R_{\mathrm{N}}$ is the coefficient of normal restitution [0,1], and $R_{\mathrm{T}}$ is the coefficient of tangential restitution $[0,1]$.

In the RockFall Analyst model, a boulder will bounce and continue its parabolic projectile motion if it maintains a higher velocity after impact, whereas rolling/sliding will occur if the velocity has decreased to some value, such as, $0.5 \mathrm{~m} / \mathrm{s}$, after impact. The simulation will stop if the exit velocity is zero (Lan et al. 2007). The final velocity of the sliding movement of the rock in the first cell plane has the same magnitude as the initial velocity of the movement in the next cell plane. The simulation will stop if the exit velocity is zero.

\subsection{Newmark and RockFall Analyst Joint Model}

The Newmark model assesses the permanent displacement and landslide occurrence probability for a seismic landslide hazard, and RockFall Analyst analyzes the sliding process of instable rock masses and describes the final scope and magnitude of special deposits. Therefore, this study established a merged Newmark and RockFall Analyst model that uses the slope displacement $\left(D_{\mathrm{n}}\right)$ output of the Newmark model as the input data of the RockFall Analyst component. This joint procedure includes the whole Newmark model and the motion trajectory simulation and rockfall spatial frequency modules of the RockFall Analyst model.

Landslide risk intensity generally means the landslide deposit magnitude. In this article, landslide intensity is expressed in terms of the rock mass units' frequency. The frequency value of a cell will remain zero if no rockfall trajectory passes and will increase by one if one rockfall trajectory passes. The value of each cell indicates its risk of suffering a rockfall, namely, the landslide deposit intensity risk. The steps of the comprehensive model of seismic landslide risk identification are shown in Fig. 1.

The dataset needed for the joint model procedure includes: (1) a seismic shaking parameter, namely PGA or Arias intensity; (2) a lithology map to analyze the effective cohesion, effective friction angle, and material unit weight; (3) a DEM to obtain the slope and aspect; (4) the sliding surface types to set the normal restitution coefficient and the tangential restitution coefficient; and (5) sliding plane thickness. Among them, the seismic shaking parameter, effective cohesion, effective friction angle, material unit weight, sliding plane thickness, and slope are the parameters of the Newmark model. The slope, aspect, normal restitution coefficient, tangential restitution coefficient, and friction angle are parameters of the RockFall Analyst model. The joint model is calculated based on raster grids.

\section{The Study Area and Model Parameters}

To verify the reliability of the joint method, the Jiuzhaigou earthquake area in Sichuan Province, a worldwide tourist attraction, was used as a case study. Related parameters needed for the joint Newmark model and RockFall Analyst model include seismic shaking parameters, geotechnical parameters, terrain parameters, and sliding surface parameters. 


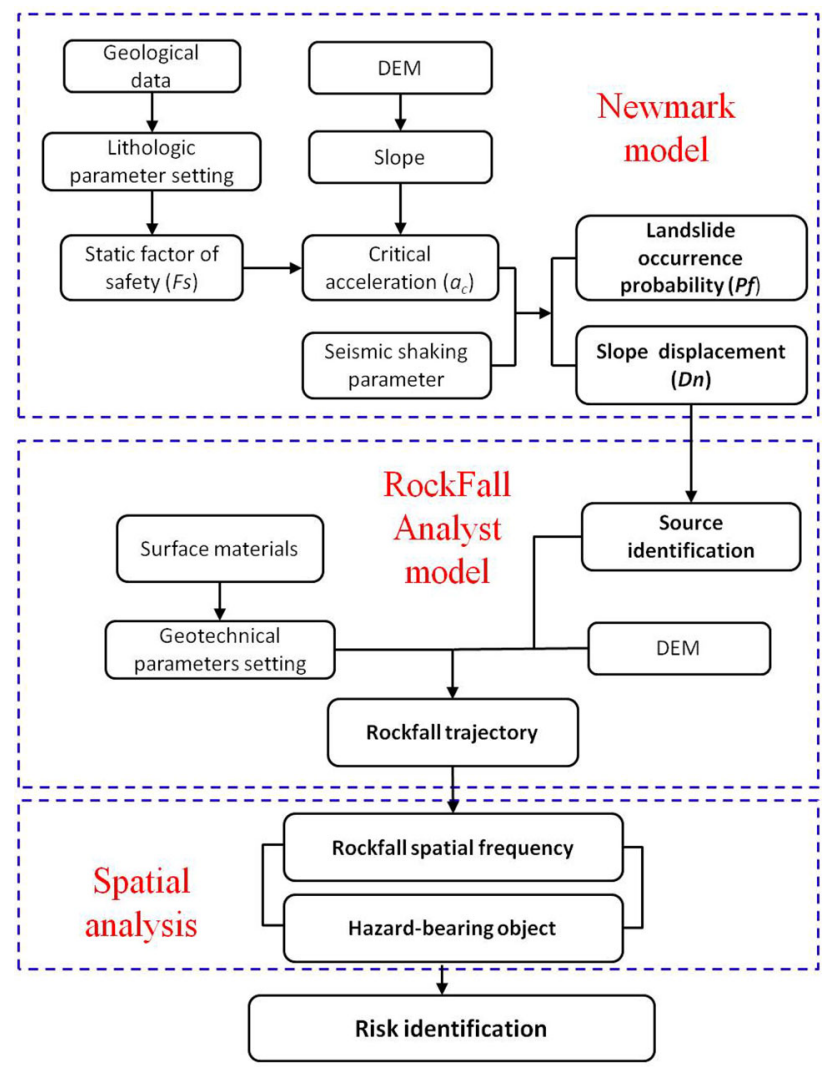

Fig. 1 A schematic diagram of the joint Newmark and RockFall Analyst model used in the Jinzhaigou Earthquake seismic landslide study. DEM digital elevation model

\subsection{Study Area}

The Jiuzhaigou Earthquake, which occurred on 8 August 2017 (Ms $=7.0$, epicenter located at $33.2^{\circ} \mathrm{N}, 103.82^{\circ} \mathrm{E}$ ) with a focal depth of $12.0 \mathrm{~km}$ in Jiuzhaigou County, Sichuan Province, China, was triggered by the reactivation of faults of the Longmenshan fault zone (Chen et al. 2018; Lei et al. 2018). The main shock of the Jiuzhaigou Earthquake started along the northwestern direction of the Huya fault (Fig. 2, fault A). It was mainly related to stress and movement along the eastern edge of the Qinghai-Tibet Plateau and was characterized by left-lateral strike-slip movement. In addition to the Huya fault, the Minjiang, Maqu-Heye, Bailongjia, and Guanggaishan-Dieshanbeilu faults (faults B, C, D, and E respectively on Fig. 2) are also distributed in the affected area, which includes parts of Jiuzhaigou, Pingwu, Wenxian, Songpan, Hongyuan, Ruo'ergai, Diebu, and Zhouqu Counties on Fig. 2. The main shock area is an alpine and canyon region in which elevations increase from east to west, with the eastern region containing many valleys. These characteristics caused the affected area to be prone to immediate and prolonged mountain hazards such as landslides. According to a field survey by Zhao et al. (2018), the immediately induced landslides numbered about 1780. Because the region is a famous tourist area that is listed as a world heritage site by UNESCO (Chen et al. 2018) and receives a large number of tourists, the number of people impacted by the quake was about 176 thousand local residents and tourists, with 25 fatalities, 525 casualties, and 6 missing people. $^{1}$

\subsection{Data and Model Parameters}

Due to the lack of Arias data, the peak ground acceleration (PGA) data needed to establish the seismic shaking parameter were collected instead of Arias intensity for the Newmark model. The PGA station data for the Jiuzhaigou main shock were obtained from the China Earthquake Administration. ${ }^{2}$ This PGA dataset includes the values in east-west, north-south, and vertical directions, and the maximum of three-direction values was used for spatial interpolation. The seismic station records show that the maximum PGA values were $185 \mathrm{~cm} / \mathrm{s}^{2}, 91.7 \mathrm{~cm} / \mathrm{s}^{2}$, and $67.7 \mathrm{~cm} / \mathrm{s}^{2}$, and the remaining values were all below $50 \mathrm{~cm} / \mathrm{s}^{2}$ (Fig. 2). With the epicenter intensity above IX, the PGA at the epicenter was thought to be greater than the critical acceleration threshold of $0.2 \mathrm{~g}\left(198 \mathrm{~cm} / \mathrm{s}^{2}\right)$ found by Wilson and Keefer (1983).

The lithological data were digitized from a 1:500,000 geological map. Based on the GB50218T-2014 (China) engineering rock mass grading standards, the rock masses were divided into five types (Fig. 3a and Table 1). The study area is dominated by hard rock, which accounts for approximately $83 \%$ of the total affected area. Based on the mechanical parameters collected in the study area and back analysis, the strength parameter values (the effective cohesion $\left(c^{\prime}\right)$, effective friction angle $\left(\varphi^{\prime}\right)$, and material unit weight $(\gamma)$ ) of these rock groups were obtained and are presented in Table 1. The thickness of the sliding plane was then set to $5,4,3$, and $2 \mathrm{~m}$ for slopes with gradients $<30^{\circ}, 30-45^{\circ}, 45-60^{\circ}$, and greater than $60^{\circ}$, respectively.

The DEM, with a spatial resolution of $90 \mathrm{~m}$, used in this study was derived from the Shuttle Radar Topography Mission (SRTM). ${ }^{3}$ Slope angle $(\alpha)$ and aspect were derived from the DEM with a pixel size of $100 \times 100 \mathrm{~m}$. Elevation of the entire study area ranges from 578 to $5465 \mathrm{~m}$, and slope angle ranges from approximately $0^{\circ}-77.24^{\circ}$. Elevation is significantly different in the eastern region of the study area, resulting in a relatively obvious gradient. The western terrain is relatively flat (Fig. 2).

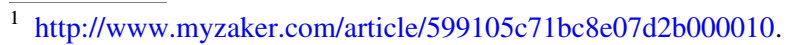

2 http://www.csi.ac.cn/manage/eqDown/05LargeEQ/201708082119M 7.0/zonghe.html.

${ }^{3}$ https://lta.cr.usgs.gov/get_data.
} 


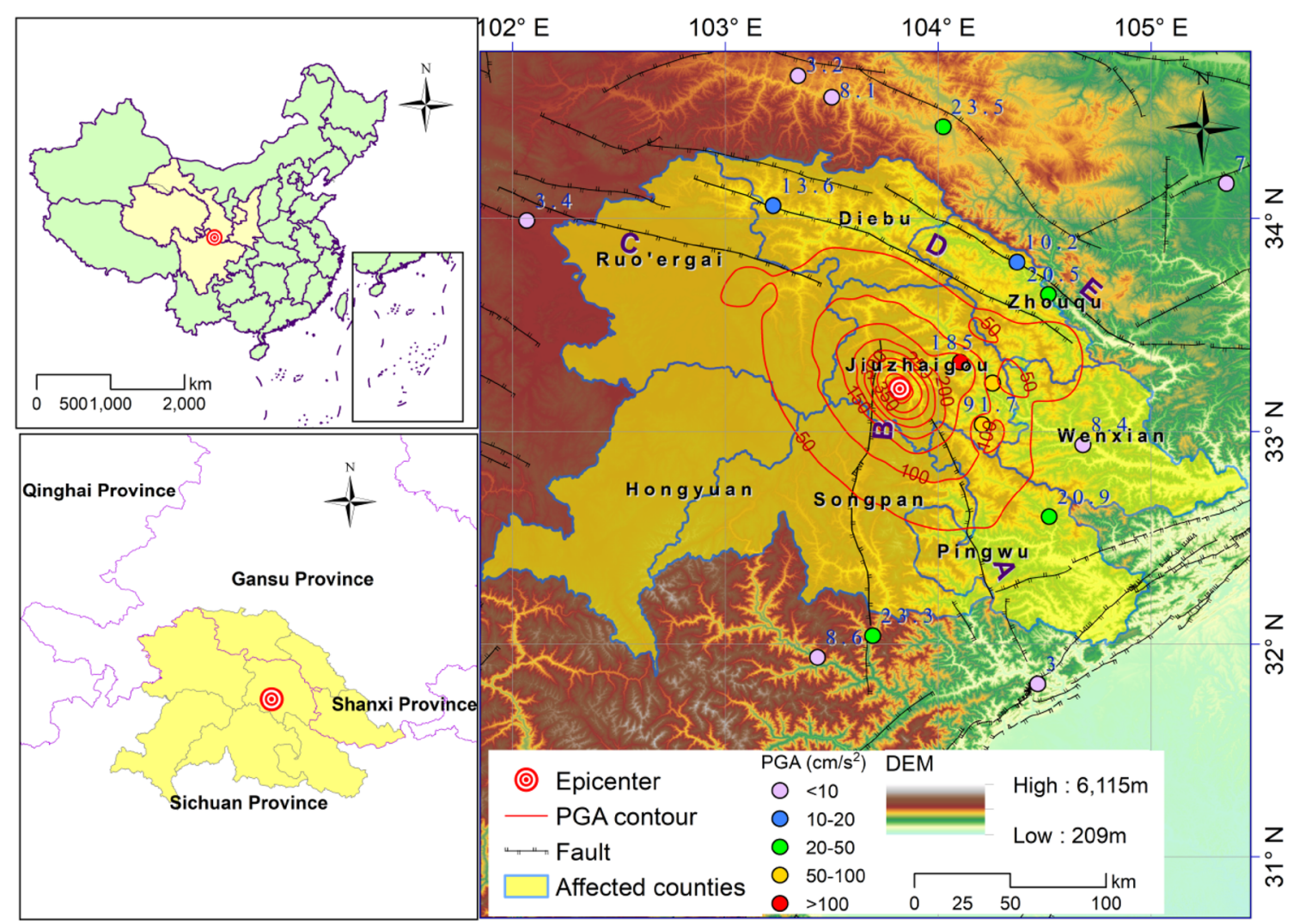

Fig. 2 The main shock area of the Jiuzhaigou Earthquake, Sichuan Province, China. Faults A, B, C, D, E represent the Huya, Minjiang, MaquHeye, Bailongjia, and Guanggaishan-Dieshanbeilu faults, respectively. $P G A$ peak ground acceleration

The sliding surface materials are important for setting the parameters of the RockFall Analyst model, which is the basis for the normal restitution coefficient, tangential restitution coefficient, and sliding surface friction angle. The types of sliding surface materials in this area are mainly associated with the vegetation cover types of the slope surface. Based on the land use map with a $250 \mathrm{~m}$ resolution and published by the Institute of Remote Sensing Applications, Chinese Academy of Sciences in 2010, ${ }^{4}$ the sliding surfaces were classified according to the standards of the Chinese Ministry of Railways (Huang and Liu 2008) and the parameters of previous studies (Lan et al. 2007). The normal restitution coefficient $\left(R_{\mathrm{n}}\right)$, tangential restitution coefficient $\left(R_{\mathrm{t}}\right)$, and friction angle parameters of each sliding surface used in this study are shown in Table 2. The parameters of the seed layer were mainly set as the default values of the RockFall Analyst model system. To facilitate further model calculations, all these data were converted into raster images with a spatial resolution of $100 \mathrm{~m}$.

\footnotetext{
${ }^{4}$ http://www.resdc.cn/data.aspx ?DATAID=99.
}

\section{Results of Road Risk Identification for the Jiuzhaigou Seismic Landslides}

The joint model procedure provides a method for the risk identification of seismic landslides on specific objects (particularly roads) based on both seismic landslide probability analysis and movement trajectory simulation to determine landslide intensity. The result of road risk identification can thus be elaborated by combining the two major parts into one model.

\subsection{Analysis of Seismic Landslide Probability}

The probability of seismic landslides, based on the results of the Newmark model and under the seismic condition of the 2017 Jiuzhaigou Earthquake, is shown in Fig. 4. Because permanent displacement corresponding to a landslide occurrence probability of 0.3 approaches the landslide-prone threshold indicated by Jibson (1993), we divide the landslide probability into groups with a cutoff value of 0.3 for high risk. All the values are classified by an equal interval of 0.1 , and the maximum value 0.335 and the minimum value 0 are also set as one level. Then landslide 
Fig. 3 Map of the engineering geological groups (a) and surface materials (b) in the impact area of the Jiuzhaigou Earthquake, Sichuan Province, China. Information on each engineering geological type is shown in Table 1
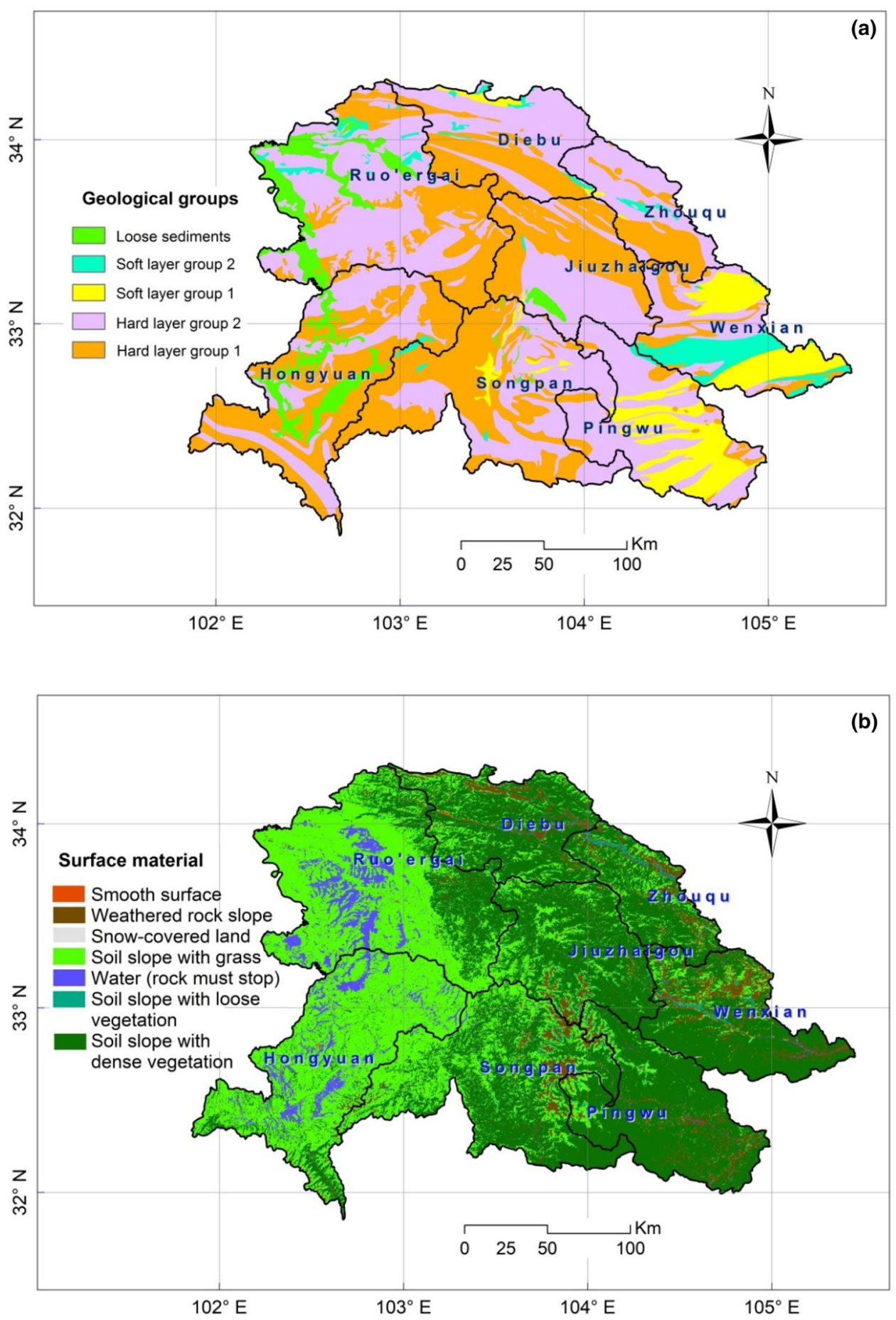

risk is defined as six levels: RL0 $(\mathrm{Pf}=0)$, RL1 $(0<$ Pf $<0.1)$, RL2 $(0.1 \leq$ Pf $<0.2)$, RL3 $(0.2 \leq \mathrm{Pf}<0.3)$, RL4 $(0.3 \leq \mathrm{Pf}<0.335)$, and RL5 ( $\mathrm{Pf}=0.335)$. In the study area, the area with the highest risk $(\mathrm{Pf}=0.335)$ accounts for $7.61 \%$ of the total, and the area of second highest landslide risk (RL4, $0.3 \leq \mathrm{Pf}<0.335)$ accounts for $13.76 \%$ (Table 3). Hence, the total area for landslide probabilities over 0.3 (risk level above RL4) is approximately $21 \%$. The permanent displacement thresholds for RL5 and RL4 are $36 \mathrm{~cm}$ and $12 \mathrm{~cm}$, respectively (Table 3).

Jiuzhaigou, northern Pingwu, western Songpan, southern Wenxian, and western Zhouqu Counties are the areas 
Table 1 Classification of engineering lithological groups and their mechanical properties

\begin{tabular}{llll}
\hline Engineering geological types & $C^{\prime}(\mathrm{kPa})$ & $\varphi^{\prime}\left({ }^{\circ}\right)$ & $\gamma\left(\mathrm{kN} / \mathrm{m}^{3}\right)$ \\
\hline Hard layer group 1: granite, diorite, basalt, andesite and gneiss & 29 & 30 & 25 \\
Hard layer group 2: marble, slate, dolomite and limestone & 25 & 27 & 22 \\
Soft layer group 1: tuff, phyllite, marl, siltstone & 20 & 22 & 20 \\
Soft layer group 2: mudstone and shale & 16 & 18 & 18 \\
Loose sediments & 11 & 14 & 17 \\
\hline
\end{tabular}

Table 2 Properties of surface materials

\begin{tabular}{llll}
\hline Surface material type & Normal restitution coefficient $\left(R_{\mathrm{n}}\right)$ & Tangential restitution coefficient $\left(R_{\mathrm{t}}\right)$ & Friction angle $\left({ }^{\circ}\right)$ \\
\hline Soil slope with dense vegetation & 0.2 & 0.6 & 30 \\
Soil slope with loose vegetation & 0.3 & 0.6 & 25 \\
Soil slope with grass & 0.3 & 0.8 & 25 \\
Water (rock must stop) & 0 & 0 & 89 \\
Weathered rock slope & 0.35 & 0.8 & 15 \\
Smooth surface & 0.4 & 0.85 & 15 \\
Snow-covered land & 0.1 & 0.1 & 89 \\
\hline
\end{tabular}

Fig. 4 Probabilistic hazard map of seismic landslides in the study area caused by the Jiuzhaigou Earthquake, Sichuan Province, China. A, B, and C indicate locations of three large landslides immediately following the earthquake (photos shown in Fig. 5)

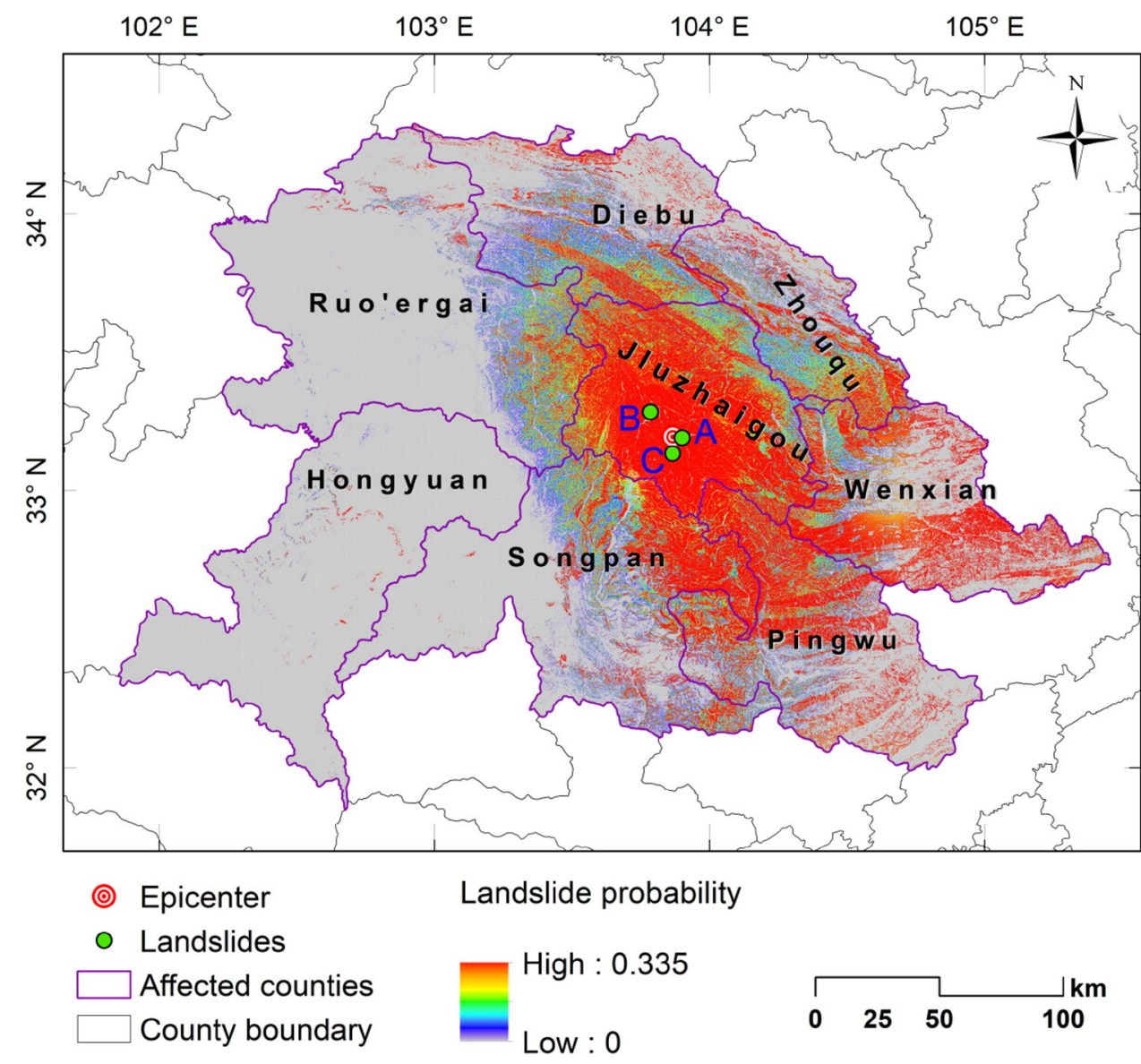


Table 3 Classification and statistics of probabilistic risk of seismic landslides

\begin{tabular}{lllr}
\hline $\begin{array}{l}\text { Risk } \\
\text { level }\end{array}$ & $\begin{array}{l}\text { Seismic landslide } \\
\text { probability (Pf) }\end{array}$ & $\begin{array}{l}\text { Thresholds of permanent } \\
\text { displacement based on Pf } \\
\text { equation }\end{array}$ & $\begin{array}{l}\text { Hazard } \\
\text { area } \\
(\%)\end{array}$ \\
\hline RL0 & 0 & - & 48.42 \\
RL1 & $0<\mathrm{Pf}<0.1$ & $1 \mathrm{~cm}$ & 20.44 \\
RL2 & $0.1 \leq \mathrm{Pf}<0.2$ & $4 \mathrm{~cm}$ & 4.95 \\
RL3 & $0.2 \leq \mathrm{Pf}<0.3$ & $7 \mathrm{~cm}$ & 4.83 \\
RL4 & $0.3 \leq \mathrm{Pf}<0.335$ & $12 \mathrm{~cm}$ & 13.76 \\
RL5 & 0.335 & $36 \mathrm{~cm}$ & 7.61 \\
\hline
\end{tabular}

most prone to seismic landslides. Among them, Jiuzhaigou, Songpan, and Pingwu Counties are located near the epicenter of the 2017 Jiuzhaigou earthquake and adjacent active fault zones; their high slope instability results from local high PGA values. On the other hand, because Wenxian County is affected by local lithological conditions, the high slope instability there is due to the low critical acceleration threshold, despite a low PGA value.

By comparison of the landslide probability from the Newmark model with the landslide distribution observed in high-resolution remote sensing images on 16 August 2017 and the field investigation performed by the National Geospatial Information Center, quantitative verification result shows that 63 out of 95 Jiuzhaigou landslides are located in areas with risk levels above RL5, accounting for $66.32 \%$ of the total. Twelve landslides are located in regions with a risk level of RL4, accounting for $12.6 \%$ of the total. Thus, $78.9 \%$ of the total landslides occurred in the high risk area, which reflects the great applicability that the Newmark model has to the simulation of unstable slopes.

Figure 5 shows some landslides that occurred immediately after the Jiuzhaigou Earthquake. ${ }^{5}$ These landslides include the Laohu Lake landslide (Fig. 5a), the group of landslides located from Heihetang Village to Jiuzhaigou Town (Fig. 5b), and the Panda Lake landslide (Fig. 5c), all of which are located in the high-risk areas identified by the Newmark model (Fig. 4). In addition, we present a figure showing the coincidence between the modeled trajectories and runout areas of real landslides (Fig. 6), which are from Google Earth.

\subsection{Instable Slope Mass Trajectory Simulation and Landslide Risk Identification for Roads}

Based on the seismic landslide probability from the Newmark model, the highest risk slopes $(\mathrm{RL}=5, \mathrm{Pf}=0.335)$ were selected for mass trajectory simulation. Each

\footnotetext{
5 Photos from China News on 12 August 2017 at https://item.btime. com/322i8ebm19482p82tepaqmp4fd9.
}

unstable slope cell was considered as one point, and only the highest potential direction was set for each point. Based on the trajectory lines, rockfall spatial frequency was further calculated, and the neighborhood $(3 \times 3)$ mean focal analysis was performed over a new raster image to obtain a continuous predicted surface for rockfall spatial frequency (the landslide intensity). The results show that the rockfall spatial frequency for the cells ranges from 0 to 73.69. As the value 1 means one unit of source rock mass $(100 \mathrm{~m} \times 100 \mathrm{~m})$ will be deposited, the maximum value of 76.39 means that the corresponding cell on the road section may suffer a risk of a deposition of 76 units of source rock mass $(100 \mathrm{~m} \times 100 \mathrm{~m})$. Based on the rockfall spatial frequency, we classified the depositional risk of seismic landslides on the area's roads into 6 levels (RR0RR5) in Table 4. The spatial statistical results (Table 4) show that $1249.58 \mathrm{~km}(53.91 \%)$ of the region's total roads $(2317.86 \mathrm{~km})$ are basically free from landslides, and they are mainly found in the western flat region. Road sections of $607.42 \mathrm{~km}$ may suffer a risk of 0.01-5 units of deposition of source rock mass, $160.74 \mathrm{~km}$ may encounter a risk of 5-10 units of deposition of source rock mass, and $198.44 \mathrm{~km}$ and $97.74 \mathrm{~km}$ can encounter the risk of 10-20 and 20-50 units of source rock mass deposition. Additionally, the risk of deposition of 50-76 units of source rock mass is most likely to affect road sections of $3.95 \mathrm{~km}$ $(0.17 \%)$, which are extremely dangerous areas and are exposed to very high risk.

The risk intensity results show that road sections throughout Jiuzhaigou, Pingwu, and Zhouqu Counties, as well as in Songpan County, are at a relatively high risk (Fig. 7). The specific road sections from Heihetang Village to Tama (Route G544, previously S301), from Heihetang Village to Yuwa and Ruo'ergai County, and from Heihetang Village to Jiuzhaigou County (city) are the most dangerous (Fig. 8a). These sections are all located in Jiuzhaigou County. The road section from Huacaopo to Yushui Town in Zhouqu County (Fig. 8b), the road section from Chuanzhushi Town to Shuijing Town in Songpan County (Fig. 8c) and that from Jiuzhaigou County (city) to Zhuyuanba Village (Route G544, previously S301) and to Yiwadaire Village (Route S205) (Fig. 8d) also have higher risks of experiencing landslides. The western regions of the study area, including Ruo'ergai, Hongyuan, and western Songpan Counties, are unlikely to experience seismic landslides.

\section{Discussion}

Disaster chains or cascading disasters are complex systems. In spite of growing awareness of the relationships between hazards, there still is no unified conceptual approach that 


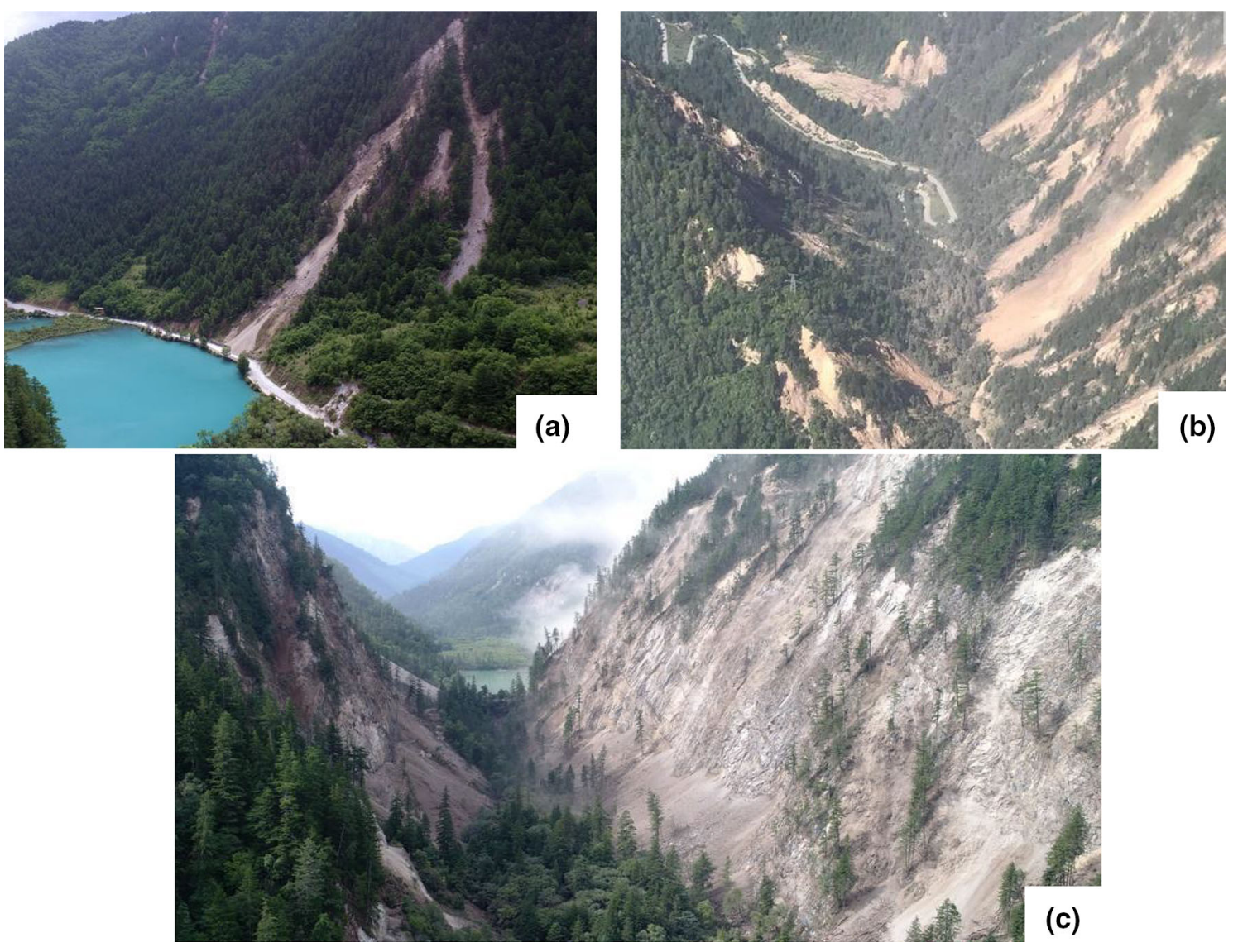

Fig. 5 Seismic landslides immediately following the Jiuzhaigou Earthquake in Sichuan Province, China: a Laohu Lake landslide; B landslides along the roads from Heihetang Village to the Jiuzhaigou Town; and $\mathbf{C}$ Panda lake landslide. The locations of $\mathbf{a}$, $\mathbf{b}$, and $\mathbf{c}$ are shown in Fig. 4 as $\mathrm{A}, \mathrm{B}$, and $\mathrm{C}$

Fig. 6 Coincidence between modeled landslide trajectories and runout areas of a southeastfacing slope near Panda Lake impacted by the 2017

Jiuzhaigou Earthquate, Sichuan Province, China. Source Base image from Google Earth

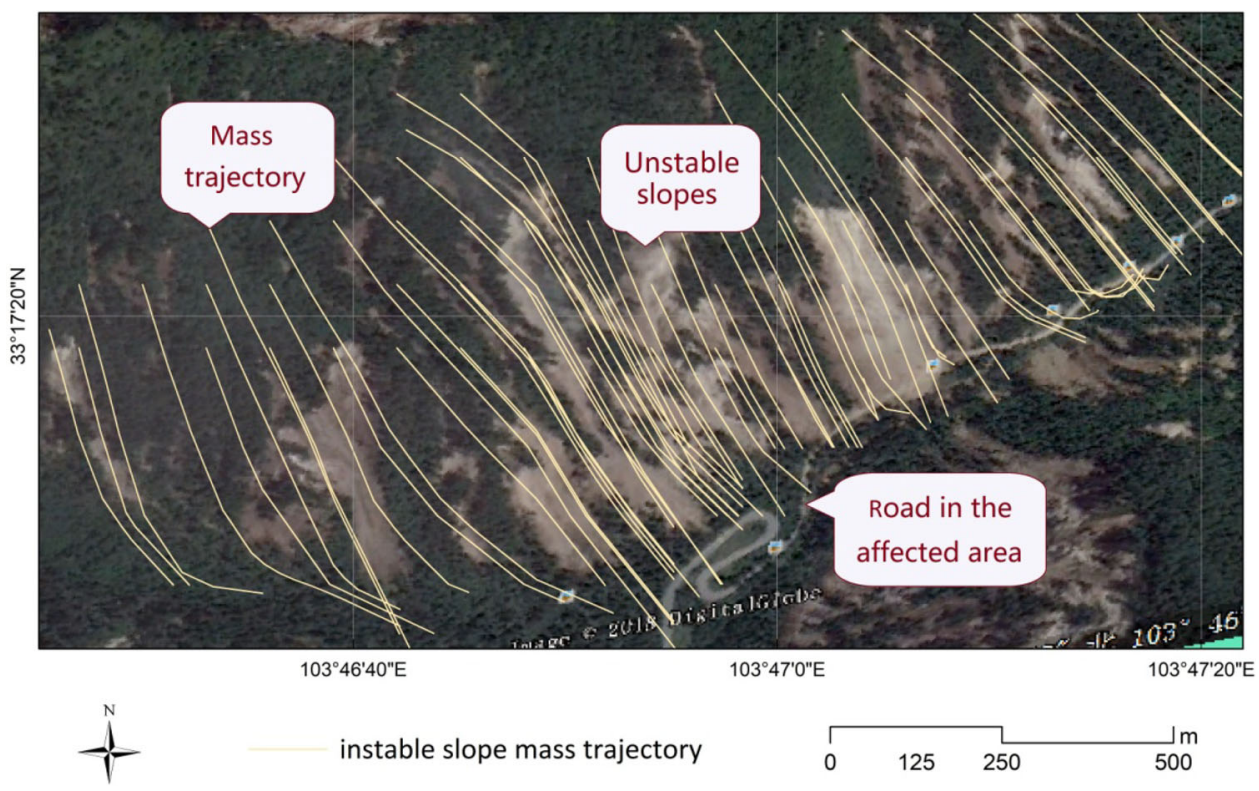


Table 4 Road risk classification and statistics under seismic landslides

\begin{tabular}{llll}
\hline $\begin{array}{l}\text { Road risk } \\
\text { level }\end{array}$ & $\begin{array}{l}\text { Agglomerated } \\
\text { rock units }\end{array}$ & $\begin{array}{l}\text { Dangerous } \\
\text { roads }(\%)\end{array}$ & $\begin{array}{l}\text { Dangerous road } \\
\text { length }(\mathrm{km})\end{array}$ \\
\hline RR0 & 0 & 53.91 & 1249.58 \\
RR1 & $<5$ & 26.21 & 607.42 \\
RR2 & $5-10$ & 6.93 & 160.74 \\
RR3 & $10-20$ & 8.56 & 198.44 \\
RR4 & $20-50$ & 4.22 & 97.74 \\
RR5 & $\geq 50$ & 0.17 & 3.95 \\
\hline
\end{tabular}

can be applied to assess cascading disaster risks (Kappes et al. 2012). In the past several decades, many efforts have been undertaken in quantitative disaster cascading impact research. Among the most prominent cascading disasters is the triggering of landslides by earthquakes. Models or methods such as the Newmark model, pseudo-static analysis, and the finite element modeling method performed well for probabilistic studies of sliding initiation and general stability of slopes under earthquake influence. But landslide intensity, another important indicator for cascading hazard and vulnerability, is seldom considered in regional seismic landslide risk identification.

In the past several decades, research on the numerical simulation of landslides has been developed, and landslide movement simulation has been undertaken that successfully represents landslide intensity. The RockFall Analyst model used in this study focuses much more on the rock fall process, and other landslide models such as the 3DDAN (Hungr) model and the D-claw (USGS) model are mainly deep-seated landslide or rainfall-induced landslide models (Delaney and Evans 2014; Sauthier et al. 2015; Gao et al. 2016; George et al. 2017). All of them are highly useful for single landslide risk (intensity) identification. In addition to landslide deposit, landslide velocity and energy are also considered in landslide risk assessments. But numerical simulation of landslides is seldom used for regional landslide risk assessment.

The joint procedure presented in this article, which couples the Newmark model and the Rockfall Analyst model based on a GIS platform, is helpful for the regional quantitative risk identification of seismic landslide impacts on specific infrastructure. Our composite model
Fig. 7 Road risk identification of the 2017 Jiuzhaigou seismic landslides in Sichuan Province, China. Letters a, b, c, d locate the dangerous road sections that are presented in detailed local maps shown in Fig. 8. The descriptions of RR0-5 are included in Table 4

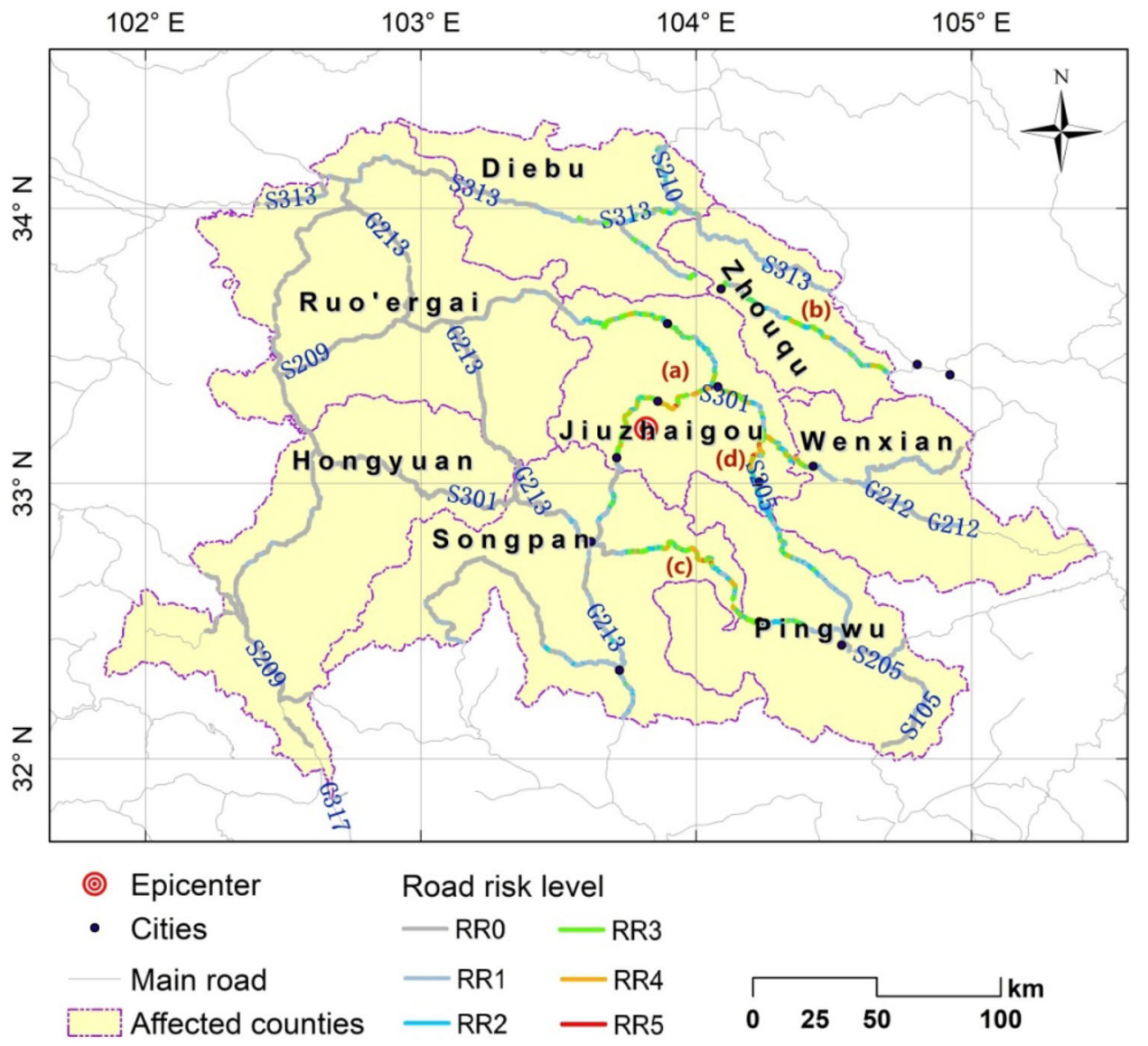



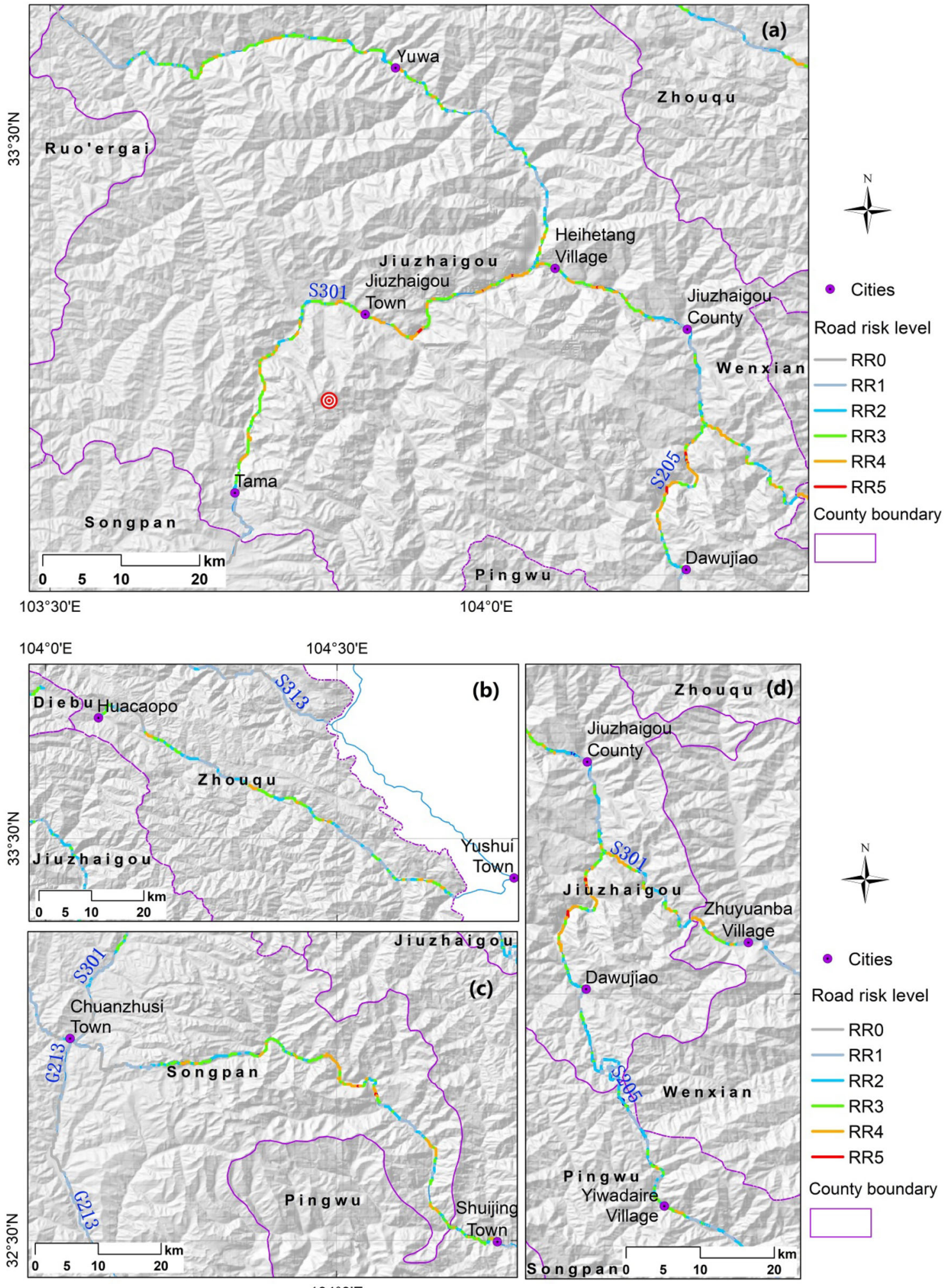

- Cities

Road risk level

- RRO

- RR1

- RR2

- RR3

- RR4

- RR5

County boundary

Fig. 8 Detailed maps of dangerous road sections in Sichuan Province, China with a high likelihood of sustaining significant impacts from future seismic events. The road sections in a-d are enlarged schematics of those in Fig. 7 (with red symbols). The descriptions of RR0-5 are shown in Table 4 
successfully highlights the comprehensive effects of landslide occurrence probability and intensity, and results in improved risk identification of seismic landslides compared to individual, stand-alone models, because the linked-model approach encompasses both the cascading relationships and effects of seismic landslides.

Although the joint method presents the risk of cascading disasters well, with its calculation based on grids, the ability to identify unstable slopes instead of grid-level cell instability needs further exploration. In addition, landslides during or after earthquakes are actually affected by a variety of factors, which includes internal environmental factors such as geology, topography, and vegetation cover as well as external environmental factors such as rainfall and human activities. In particular, landslides are greatly affected by precipitation (Guzzetti et al. 2007; Huang et al. 2016), especially when an earthquake is coupled with rainfall. Therefore, lack of consideration of precipitation for seismic landslides is a significant defect, and how to add rainfall parameters to seismic landslide analysis in our joint model method should be further studied.

Jiuzhaigou is a tourist area that is famous worldwide. In addition to local residents, the population affected by the 2017 quake may also include a large number of tourists. For example, over five million tourists travelled to Jiuzhaigou in 2015, with the majority visits taking place in the summer and autumn. The precipitation of this region also is concentrated in July, August, September, and October-in the past 60 years, heavy rainfall has occurred in these summer and autumn months (Zhou et al. 2006). Thus, the tourist season and the rainfall season coincide. As roads are important transportation routes, where local and tourist populations inevitably converge, studies of road risk identification of Jiuzhaigou seismic landslides have important practical significance for post-disaster local restoration and reconstruction, as well as tourist travel.

\section{Conclusion}

Analysis of multihazard disaster risk is very complicated. To cope with this challenge, new methodologies should be explored. In this study, we coupled the Newmark and RockFall Analyst models to achieve better quantitative risk identification of seismic landslide impacts on Sichuan Province's roads. Our method considered both the landslide occurrence probability and landslide intensity to indicate the cascading effects of seismic landslides. The spatial seismic landslide occurrence probability analysis, unstable slope trajectory simulation, and risk identification are quantitative, which accurately reflects the cascading relationships of seismic landslides and their risk formation process.
According to this joint method, the results of a case study of the Jiuzhaigou Earthquake show that approximately $21.37 \%$ of the study area falls into a high risk category, and a total of $3.95 \mathrm{~km}$ of road sections are affected by an extremely high risk of large landslides, which could cause severe damage to roads. Based on verification that uses post-earthquake remote sensing imageinterpretation results and field disaster investigation in existing studies and reports, the simulated result from this joint method is highly consistent with the results achieved in existing research. The joint method also can be used for risk identification for river courses, bridges, buildings, and other infrastructure as well as for settlements.

Acknowledgements The authors would like to express sincere appreciation to the reviewers, the editors, and Dr. Yuming Wu for their valuable comments and suggestions, which were helpful in improving the article. This work was financially supported by the Pioneer Project of the Chinese Academy of Sciences (Grant No. XDA19040304), the National Key R\&D Program of China (2017YFC150290402), and the Cultivate Project of Chinese Academy of Sciences (Grant No. TSYJS03), for which grateful appreciation is expressed.

Open Access This article is distributed under the terms of the Creative Commons Attribution 4.0 International License (http://crea tivecommons.org/licenses/by/4.0/), which permits unrestricted use, distribution, and reproduction in any medium, provided you give appropriate credit to the original author(s) and the source, provide a link to the Creative Commons license, and indicate if changes were made.

\section{References}

Arias, A. 1970. A measure of earthquake intensity. In Seismic design for nuclear power plants, ed. R.J. Hansen, 438-483. Cambridge: Massachusetts Institute of Technology Press.

Bai, S., J. Wang, Z. Zhang, and C. Cheng. 2012. Combined landslide susceptibility mapping after Wenchuan earthquake at the Zhouqu segment in the Bailongjiang basin, China. Catena 99(4): 18-25.

Biondi, G., E. Cascone, and M. Maugeri. 2002. Flow and deformation of sandy slopes. Soil Dynamics and Earthquake Engineering 22(12): 1103-1114.

Bray, J.D., and E.M. Rathje. 1998. Earthquake-induced displacements of solid-waste landfills. Journal of Geotechnical and Geoenvironmental Engineering 124(3): 242-253.

Chen, X.Q., J.G. Chen, P. Cui, Y. You, K.H. Hu, and Z.J. Yang. 2018. Assessment of prospective hazards resulting from the 2017 earthquake at the world heritage site Jiuzhaigou valley, Sichuan, China. Journal of Mountain Science 15(4): 779-792.

Chen, Z., X. Meng, Y. Yin, T. Dijkstra, M. Winter, and J. Wasowski. 2016. Landslide research in China. Quarterly Journal of Engineering Geology and Hydrogeology 49(4): qjegh2016-100.

Chousianitis, K., V.D. Gaudio, I. Kalogeras, and A. Ganas. 2014. Predictive model of arias intensity and Newmark displacement for regional scale evaluation of earthquake-induced landslide hazard in Greece. Soil Dynamics and Earthquake Engineering 65: 11-29.

Chousianitis, K., V. Del Gaudio, N. Sabatakakis, K. Kavoura, G. Drakatos, and G.D. Bathrellos. 2016. Assessment of earthquake- 
induced landslide hazard in Greece: From arias intensity to spatial distribution of slope resistance demand. Bulletin of the Seismological Society of America 106(1): 174-188.

Cui, P., F.Q. Wei, X.Q. Chen, and S.M. He. 2008. Geo-hazards in Wenchuan earthquake area and counter measures for disaster reduction. Bulletin of Chinese Academy of Sciences 23(4): 317-323 (in Chinese).

Del Gaudio, V. 2003. An approach to time-probabilistic evaluation of seismically induced landslide hazard. Bulletin of the Seismological Society of America 93(2): 557-569.

Delaney, K.B., and S.G. Evans. 2014. The 1997 Mount Munday landslide (British Columbia) and the behaviour of rock avalanches on glacier surfaces. Landslides 11(6): 1019-1036.

Dorren, L.K.A. 2003. A review of rockfall mechanics and modelling approaches. Progress in Physical Geography 27(1): 69-87.

Elgamal, A.W.M., A.M. Abdel-Ghaffar, and J.H. Prevost. 1987. 2-D elastoplastic seismic shear response of earth dams: Theory. Journal of Engineering Mechanics 113(5): 689-701.

Evans, S.G., and O. Hungr. 1993. The assessment of rockfall hazard at the base of talus slopes. Revue Canadienne de Géotechnique 30(4): 620-636.

Gao, Y., L.I. Bin, and G. Wang. 2016. Motion feature and numerical simulation analysis of Jiweishan landslide with rapid and long run-out. Journal of Engineering Geology 24(3): 425-434 (in Chinese)

George, D.L., R.M. Iverson, and C.M. Cannon. 2017. New methodology for computing tsunami generation by subaerial landslides: Application to the 2015 Tyndall Glacier landslide, Alaska. Geophysical Research Letters 44(14): 7276-7284.

Guzzetti, F., G. Crosta, R. Detti, and F. Agliardi. 2002. STONE: A computer program for the three-dimensional simulation of rockfalls. Computers and Geosciences 28(9): 1079-1093.

Guzzetti, F., S. Peruccacci, M. Rossi, and C.P. Stark. 2007. Rainfall thresholds for the initiation of landslides in central and southern Europe. Meteorology and Atmospheric Physics 98(3-4): 239-267.

Guzzetti, F., P. Reichenbach, and S. Ghigi. 2004. Rockfall hazard and risk assessment along a transportation corridor in the Nera valley, central Italy. Environmental Management 34(2): 191-208.

Harp, E.L., and R.C. Wilson. 1995. Shaking intensity thresholds for rock falls and slides: Evidence from the Whittier Narrows and Superstition Hills earthquake strong motion records. Bulletin of the Seismological Society of America 85(6): 1739-1757.

Hsieh, S.Y., and C.T. Lee. 2011. Empirical estimation of the Newmark displacement from the Arias intensity and critical acceleration. Engineering Geology 122(1): 34-42.

Huang, Q.X., J.L. Wang, and X. Xue. 2016. Interpreting the influence of rainfall and reservoir infilling on a landslide. Landslides 13(5): 1139-1149.

Huang, R.Q., and W.H. Liu. 2008. Study on the movement characteristics of rolling rock blocks on platform. Advances in Earth Science 23(5): 517-523 (in Chinese).

Jibson, R.W. 1993. Predicting earthquake-induced landslide displacements using Newmark's sliding block analysis. Transportation Research Record 1411: 9-17.

Jibson, R.W. 2007. Regression models for estimating co-seismic landslide displacement. Engineering Geology 91(2): 209-218.

Jibson, R.W., and D.K. Keefer. 1993. Analysis of the seismic origin of landslides: Examples from the New Madrid seismic zone. Geological Society of America Bulletin 105(105): 521-536.

Jibson, R.W., E.L. Harp, and J.M. Michael. 2000. A method for producing digital probabilistic seismic landslide hazard maps. Engineering Geology 58(3-4): 271-289.
Kappes, M.S., M. Keiler, K.V. Elverfeldt, and T. Glade. 2012. Challenges of analyzing multi-hazard risk: A review. Natural Hazards 64(2): 1925-1958.

Lan, H., C.D. Martin, and C.H. Lim. 2007. Rockfall analyst: A GIS extension for three-dimensional and spatially distributed rockfall hazard modeling. Computers and Geosciences 33(2): 262-279.

Lei, H., X. Wang, H. Hou, L. Su, D. Yu, and H. Wang. 2018. The earthquake in Jiuzhaigou County of Northern Sichuan, China on August 8, 2017. Natural Hazards Journal of the International Society for the Prevention and Mitigation of Natural Hazards 90(2): 1021-1030.

Leshchinsky, D., and S. Ka-Ching. 1994. Pseudo-static seismic stability of slopes: Design charts. Journal of Geotechnical Engineering 120(9): 1514-1532.

Ling, H.I, and A.D. Cheng. 1997. Rock sliding induced by seismic force. International Journal of Rock Mechanics and Mining Sciences 34(6): 1021-1029.

Macciotta, R., C.D. Martin, N.R. Morgenstern, and D.M. Cruden. 2016. Quantitative risk assessment of slope hazards along a section of railway in the Canadian Cordillera - a methodology considering the uncertainty in the results. Landslides 13(1): 115-127.

Newmark, N.M. 1965. Effects of earthquakes on dams and embankments. Geotechnique 15(2): 139-160.

Owen, L.A., U. Kamp, G.A. Khattak, E.L. Harp, D.K. Keefer, and M.A. Bauer. 2008. Landslides triggered by the 8 October 2005 Kashmir earthquake. Geomorphology 94(1-2): 1-9.

Parsons, T., C. Ji, and E. Kirby. 2009. Stress changes from the 2008 Wenchuan earthquake and increased hazard in the Sichuan basin. Nature 454(7203): 509-510.

Pizziolo, M. 2015. Rockfall runout, Mount Cimone area, EmiliaRomagna Region, Italy. Journal of Maps 11(4): 598-605.

Pradel, D., P.M. Smith, J.P. Stewart, and G. Raad. 2005. Case history of landslide movement during the Northridge earthquake. Journal of Geotechnical and Geoenvironmental Engineering 131(11): 1360-1369.

Qi, S., X. Li, S. Guo, Z. Zhan, and H. Liao. 2015. Landslide risk zonation along mountainous highway considering rock mass classification. Environmental Earth Sciences 74(5): 4493-4505.

Rathje, E.M., and G. Antonakos. 2011. A unified model for predicting earthquake-induced sliding displacements of rigid and flexible slopes. Engineering Geology 122(1): 51-60.

Rathje, E.M., and G. Saygili. 2009. Probabilistic assessment of earthquake-induced sliding displacements of natural slopes. Bulletin of the New Zealand Society for Earthquake Engineering 42(1): 18-27.

Rodríguez-Peces, M.J., J. García-Mayordomo, J.M. Azañón, and A. Jabaloy. 2014. GIS application for regional assessment of seismically induced slope failures in the Sierra Nevada Range, South Spain, along the Padul Fault. Environmental Earth Sciences 72(7): 2423-2435.

Sauthier, C., M. Pirulli, G. Pisani, C. Scavia, and V. Labiouse. 2015. Numerical modelling of gravel unconstrained flow experiments with the DAN3D and RASH3D codes. Computers and Geosciences 85(Part A): 81-90.

Saygili, G., and E.M. Rathje. 2008. Empirical predictive models for earthquake-induced sliding displacements of slopes. Journal of Geotechnical and Geo-environmental Engineering 134(6): 790-803.

Seed, H.B., K.L. Lee, I.M. Idriss, and F.I. Makdisi. 1975. The slides in the San Fernando dams during the earthquake of February 9, 1971. Geotechnical Special Publication 101(7): 651-688.

Shi, P.J., N. Li, Q. Ye, W.J. Dong, G.Y. Han, and W.H. Fang. 2010. Research on integrated disaster risk governance in the context of global environmental change. International Journal of Disaster Risk Science 1(1): 17-23. 
Sun, D., L. Wang, H. Wang, M.A. Yinsheng, C. Zhou, and J. Cui. 2013. Analysis of the Wenchuan Ms 8.0 earthquake's co-seismic stress and displacement change by using the finite element method. Acta Geologica Sinica 87(4): 1120-1128.

Wilson, R.C., and D.K. Keefer. 1983. Dynamic analysis of a slope failure from the 6 August 1979 Coyote Lake, California, Earthquake. Bulletin of the Seismological Society of America 73(3): 863-877.

Yuan, R.M., Q.H. Deng, Dickson Cunningham, Z.J. Han, D.L. Zhang, and B.L. Zhang. 2016. Newmark displacement model for landslides induced by the 2013 Ms 7.0 Lushan earthquake, China. Frontiers of Earth Science 10(4): 740-750.

Zhang, Y.S., Z.H. Yang, C.B. Guo, and G.L. Guo. 2017. Predicting landslide scenes under potential earthquake scenarios in the
Xianshuihe fault zone, southwest China. Journal of Mountain Science 14(7): 1262-1278.

Zhang, Z., S. Yuan, D. Qi, and M. Zhang. 2014. The Lushan earthquake and the giant panda: Impacts and conservation. Integrative Zoology 9(3): 376-388.

Zhao, D., C. Qu, X. Shan, W. Gong, Y. Zhang, and G. Zhang. 2018. INSAR and GPS derived co-seismic deformation and fault model of the 2017 Ms7.0 Jiuzhaigou earthquake in the northeast Bayanhar block. Tectonophysics 726: 86-99.

Zhou, C.Y., Y.Q. Li, and J. Peng. 2006. Features and variations of precipitation in Jiuzhaigou-Huanglong tourist scenes. Resources Science 28(1): 113-119 (in Chinese). 